\title{
Response conflict reverses priming: A replication
}

\author{
W. TRAMMELL NEILL and TODD A. KAHAN \\ State University of New York, Albany, New York
}

\begin{abstract}
Subjects named target words that followed a masked prime word of 33-msec (Experiments $1 \mathrm{~A}$ and 1B) or 200-msec (Experiment 2) duration. The target word was either presented alone or accompanied by an interleaved distractor word. Targets presented alone were named more quickly following an identical prime than following an unrelated prime (repetition priming). In Experiment $1 \mathrm{~A}$, targets with distractors were named more slowly following an identical prime than following an unrelated prime (negative priming), replicating Milliken, Joordens, Merikle, and Seiffert (Psychological Review, 1998). In Experiments 1B and 2, repetition priming was reduced, although not reversed, for targets with distractors. The results of all three experiments are opposite to the usual finding of enhanced priming for perceptually degraded targets and suggest that response conflict engages retrospective mechanisms that counteract the facilitatory effects of priming.
\end{abstract}

If one either attends to a word or passively perceives it, reaction time $(\mathrm{RT})$ is typically facilitated if the same word soon appears as a target for response (repetition priming). Responses to words or objects that are related to the initially perceived word are also likely to be facilitated (semantic priming or associative priming). However, if a word is deliberately ignored, responses to the same word, a related word, or a related object may subsequently be retarded relative to responses to an unrelated word or object (Neill, 1977; Neill \& Westberry, 1987; Tipper \& Baylis, 1987; Tipper \& Driver, 1988; Yee, 1991). The latter effect, negative priming, has usually been demonstrated in selective attention tasks, in which target stimuli are accompanied by distracting stimuli. Thus, on a prime trial, the subject responds to a target while ignoring a distractor; negative priming occurs if the prime-trial distractor reappears as the target stimulus on a subsequent probe trial. It has therefore been commonly assumed that negative priming is a consequence of selective attention to the prime-trial target.

Selective attention on the probe trial also appears to be critical to negative priming. Although in some experiments negative priming has been found without distracting stimuli on probe trials (Neill, Terry, \& Valdes, 1994; Neill \& Westberry, 1987), the more typical finding is that negative priming is reduced (Moore, 1994) or even reversed (Lowe, 1979; Tipper \& Cranston, 1985) for nonconflict probes. A series of experiments by Milliken and colleagues suggests that selective attention on the probe trial may in fact be sufficient to cause negative priming,

Portions of this research were presented at the 37 th Annual Meeting of the Psychonomic Society, Chicago, November 1996. We are indebted to Maria Cianciulli, Heather Clark, Jennifer Hein, and Christopher Nuzzi for assistance with data collection. We are also grateful to Bruce Milliken, Michael Kane, and an anonymous reviewer for helpful comments on our initial manuscript. Please direct correspondence to W. T. Neill, Department of Psychology, State University of New York, Albany, NY 12222 (e-mail: neill@cnsibm.albany.edu). even in the absence of selective attention (as usually understood) during presentation of the priming stimulus (Milliken \& Joordens, 1996; Milliken, Joordens, Merikle, \& Seiffert, 1998; Milliken, Joordens, Tipper, Merikle, \& Seiffert, 1994).

In one set of experiments, Milliken et al. (1998; Milliken et al., 1994) presented a white prime word followed by a red target word to be named by the subject. In some experiments, the red target word was interleaved with a green distractor word. If subjects were instructed to attend to the prime word, positive (facilitatory) priming occurred for an identical target word regardless of whether it was accompanied by a distractor. In other experiments, subjects were instructed to ignore the prime, subjects were given no instructions regarding the prime, or the prime was rendered unreportable by short exposure ( $33 \mathrm{msec})$ and a masking pattern. If the target word was presented alone, the expected positive priming effects were again obtained. However, if the target word was accompanied by a distractor, the effects were reversed to negative priming. Because there was no target to which subjects responded during the prime presentation, negative priming cannot be attributed to distractor inhibition during selective attention to a target. Indeed, in the case of masked primes, it is difficult to argue that the prime words were deliberately ignored.

A potential criticism of the Milliken et al. experiments is that presence or absence of distractors was varied only between experiments. As a consequence, subjects had foreknowledge of whether the target would be accompanied by a distractor. Such foreknowledge might plausibly affect how subjects processed the prime word: For example, subjects expecting response competition might be more likely to engage inhibitory mechanisms during presentation of the prime. In order to conclude that the distractor word is critical to negative priming, it is necessary to ensure that prime processing is held constant. This was accomplished in the present experiments by varying the presence or absence of a distractor word randomly from trial to trial. 
Another modification here of the Milliken et al. procedures was to counterbalance the colors used for the target and distractor words. The Milliken et al. results could, in principle, be explained by differential processing times for red versus green words. For example, if green words are read more quickly than red words, priming the red target word might cause greater confusability or competition, owing to increased temporal overlap with processing of the green distractor. However, in the absence of a distractor, such priming would only facilitate performance.

Apart from the modifications above, we closely duplicated the procedures of Milliken et al. In Experiment 1A, the prime exposure duration was $33 \mathrm{msec}$, at which most subjects in the Milliken et al. experiments were unable to report the presence of the word. Experiment 1B was conducted as a later replication with a new subject sample. For further comparison with the results of Milliken et al., prime exposure duration was lengthened in Experiment 2 to $200 \mathrm{msec}$, at which the word was clearly visible.

\section{METHOD}

\section{Subjects}

Undergraduate students enrolled in introductory psychology courses at the State University of New York, Albany, participated in order to fulfill experiment requirements. The subjects were tested in individual sessions of approximately $35-45 \mathrm{~min}$. Thirty subjects participated in Experiment 1A, 44 in Experiment 1B, and 30 in Experiment 2 .

\section{Stimuli and Apparatus}

Stimuli were presented on a Vivitron 1572 color monitor controlled by a Gateway 2000 PC-compatible microcomputer. The experiments were programmed with Micro Experimental Laboratory (Schneider, 1988), and responses were detected by a voice key interfaced with a Micro Experimental Laboratory Response Box. Following Milliken et al., stimulus words were BOARD, FLUTE, TABLE, PILOT, CLOUD, QUEEN, TIGER, GUEST, GLASS, PRIZE, BAKER, and CLERK in uppercase letters.

The letters of the stimulus words were always displayed with intervening spaces, so that target-word letters could alternate with distractor-word letters on trials that included a distractor word Each display was approximately $3 \mathrm{~cm}$ wide and was either $.5 \mathrm{~cm}$ high (with no distractor) or $1 \mathrm{~cm}$ high (with distractor).

\section{Procedure}

The subjects were instructed at the beginning of the experiment that they would be shown words in different colors, and that their task was to quickly name words shown in a specified color. The target words were specified as red for half of the subjects, and green for the other half. The subjects were instructed to ignore distracting words when present; no explicit mention was made of the prime words preceding the targets.

Each trial began with a fixation cross centered on the monitor screen for $2,000 \mathrm{msec}$. The fixation cross was replaced by a blank screen for $250 \mathrm{msec}$, and then a premask of five ampersands (\&\&\&\&\&) for $500 \mathrm{msec}$. A randomly selected prime word was displayed for $33 \mathrm{msec}$ (Experiments 1A and 1B) or $200 \mathrm{msec}$ (Experiment 2), followed by a 500 -msec postmask of five ampersands. A target word then appeared, centered $.25 \mathrm{~cm}$ above or below the fixation position. The target word was identical to the prime word on a random half of the trials (primed) and was a different word on the remaining trials (unprimed).
A distractor word appeared in the color (red or green) opposite to that of the target on a random half of the trials. The distractor word always differed from both the prime and the target word. Letters of the distractor word were alternated with letters of the target word (e.g., QbUoEaErNd, where lettercase in this example corresponds to different colors). If the target word was centered above fixation, the distractor was centered below, and vice versa. Thus, target and distractor words differed by vertical alignment as well as color, although only color served to cue the target identity. Target words, and distractors if present, remained in view until the subject's response.

Each subject received 20 practice trials and 240 experimental trials. At the end of Experiments $1 \mathrm{~A}$ and 1B, the subjects were asked whether they noticed any words other than the red or green targets and distractors. Because the prime words in Experiment 2 were clearly visible, no attempt was made to assess subjects' awareness of the primes in that experiment.

\section{RESULTS}

\section{Experiment 1A}

Of the 30 subjects, 13 reported awareness of the prime. Preliminary analyses failed to yield any significant differences between aware and unaware subjects. (A significance level of $\alpha=.05$ was used for all statistical tests.) Subjects made errors (or failed to activate the voice key) on $3.6 \%$ of the trials; error rates did not vary significantly across conditions. Mean RT was slower overall with a distractor present $(704 \mathrm{msec})$ than without a distractor $(617 \mathrm{msec})\left[F(1,29)=99.37, M S_{\mathrm{e}}=2,254\right]$. Mean RT to primed targets and unprimed targets did not differ (both $661 \mathrm{msec}$ ). However, priming interacted significantly with presence or absence of a distractor $\left[F(1,29)=8.41, M S_{\mathrm{e}}=\right.$ 589]. Planned contrasts indicated that RT for targets presented alone was faster if they were primed $(611 \mathrm{msec})$ than if they were unprimed $(624 \mathrm{msec})[t(29)=2.08]$; but RT for targets accompanied by distractors was slower if they were primed $(710 \mathrm{msec})$ than if they were unprimed $(697 \mathrm{msec})[t(29)=2.06]$.

\section{Experiment 1B}

Of the 44 subjects, 29 reported awareness of the prime. There were no significant differences between aware and unaware subjects. More errors occurred on trials with a distractor $(1.5 \%)$ than on trials without a distractor $(0.5 \%)\left[F(1,43)=25.17, M S_{\mathrm{e}}=6.65\right]$; no other effects on errors were significant. RT was faster for primed targets $(559 \mathrm{msec})$ than for unprimed targets $(572 \mathrm{msec})$ $\left[F(1,43)=12.94, M S_{\mathrm{e}}=543\right]$, and faster for targets presented alone ( $520 \mathrm{msec})$ than for targets accompanied by a distractor $(610 \mathrm{msec})\left[F(1,43)=340.32, M S_{\mathrm{e}}=1,053\right]$. Priming interacted with presence or absence of a distractor $\left[F(1,43)=6.79, M S_{\mathrm{e}}=195\right]$, reflecting a smaller positive priming effect with a distractor $(7 \mathrm{msec})$ than without $(18 \mathrm{msec})$. Both priming effects were statistically significant $[t(43)=2.40$ and $t(43)=6.09$, respectively]

\section{Experiment 2}

Subjects made errors (or failed to activate the voice key) on $2.9 \%$ of trials; error rates did not differ significantly across conditions. As in Experiment 1, mean RT was faster 


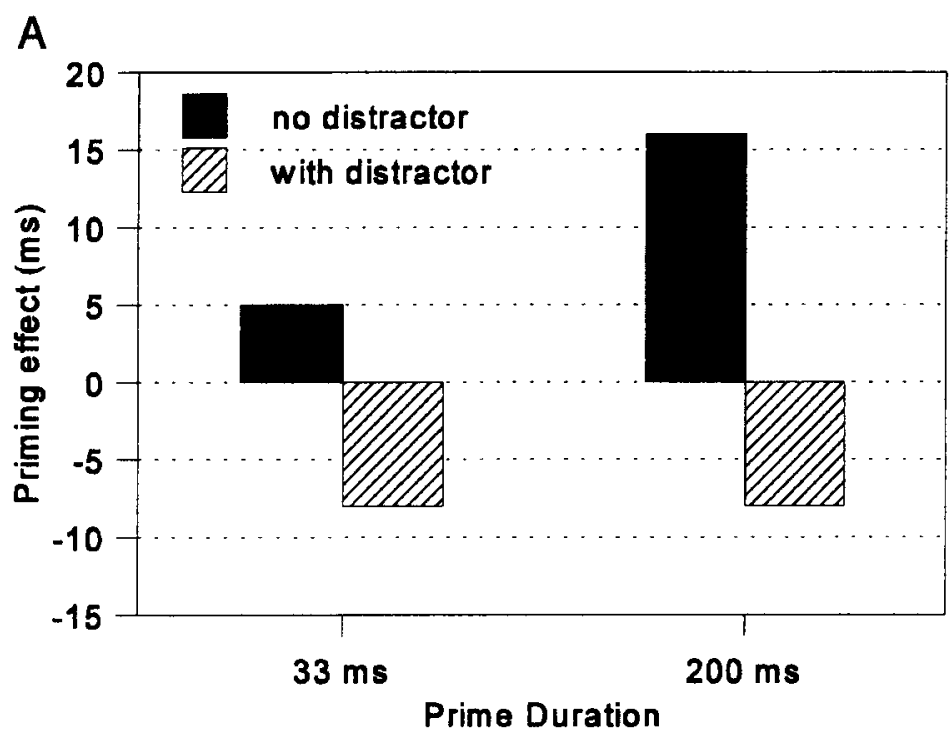

B

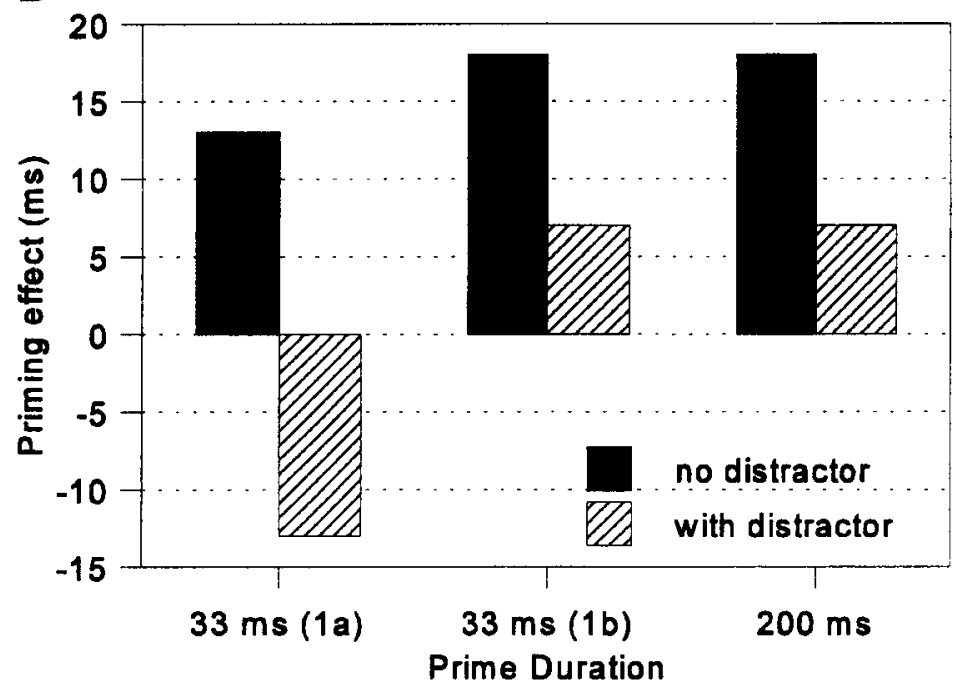

Figure 1. Priming effects as a function of prime duration and distractor presence: (A) Milliken, Joordens, Merikle, and Seiffert (1998); Milliken, Joordens, Tipper, Merikle, and Seiffert (1994). (B) The present experiments.

for targets presented alone $(541 \mathrm{msec})$ than for targets with distractors $(645 \mathrm{msec})\left[F(1,29)=220.55, M S_{\mathrm{e}}=2,976\right]$. Here, however, mean RT was also faster overall for identical targets $(587 \mathrm{msec})$ than for unrelated targets $(599 \mathrm{msec})$ $\left[F(1,29)=11.02, M S_{\mathrm{e}}=847\right]$. Relation to the prime again interacted with presence or absence of a distractor $\left[F(1,29)=5.34, M S_{\mathrm{e}}=299\right]$, reflecting a smaller positive priming effect for targets with distractors $(7 \mathrm{msec})$ than for targets without $(18 \mathrm{msec})$. Only the latter priming effect was statistically significant $[t(29)=4.46]$.

\section{DISCUSSION}

As can be seen in Figure 1, the pattern of results in Experiment $1 \mathrm{~A}$ closely replicated that of Milliken et al.:
When the target word was presented alone, an identical prime facilitated RT by $13 \mathrm{msec}$; however, when the target was accompanied by a distractor, an identical prime actually retarded RT by $13 \mathrm{msec}$. Because distractor presence was unpredictable, the reversal of positive repetition priming to negative priming cannot be attributed to differential processing strategies during presentation of the priming word.

On the other hand, in the procedurally identical Experiment $1 \mathrm{~B}$, significant, albeit diminished, positive priming was found when the the target was accompanied by a distractor. We note that subjects in Experiment 1B were more likely to have previously participated in other experiments in which they were instructed to attempt to identify a masked word. Although the percentage of sub- 
jects reporting awareness of the masked word was somewhat higher in Experiment 1B (66\%) than in Experiment $1 \mathrm{~A}(43 \%)$, awareness did not interact significantly with priming effects in either experiment. Nonetheless, it is possible that the protocols for assessing awareness were not sufficiently sensitive to detect differences in processing strategy.

The results of Experiment 2, in which the prime was clearly visible, were virtually identical to Experiment $1 \mathrm{~B}$, and as such, they differed from those of Milliken et al. (1994) in comparable conditions. ${ }^{1}$ It may be noted that Milliken et al. (1998, Experiment 4) did find positive priming for targets accompanied by distractors if subjects were explicitly instructed to attend to the prime under otherwise similar conditions. Hence, it is possible that a greater proportion of our subjects spontaneously opted to attend to the prime.

Taken together, the three experiments indicate that an actual reversal of priming from positive to negative by distractor presence is replicable, but rather fragile. On the other hand, it may be of greater theoretical consequence that repetition priming was reduced by presence of a distractor in all three experiments. This result is surprising, because repetition priming is typically enhanced if targets are perceptually degraded (see, e.g., Besner \& Swan, 1982; Norris, 1984). Indeed, Neill, Kahan, and VerWys (1996) found greater positive priming for displays similar to those used here if a noise pattern of diagonal lines was superimposed on the target display. Thus, it seems likely that postperceptual (conceptual or response-level) processes, rather than perceptual interference, are responsible for the reduction and/or reversal of repetition priming in the present experiments.

As discussed in the introduction, it has been found in several experiments that negative priming by ignored distractors is reversed to positive priming if probe targets are not also accompanied by distractors (Lowe, 1979; Tipper \& Cranston, 1985; see also Neill \& Valdes, 1996). Thus, when the conditions for negative priming are removed, facilitatory effects of the repetition emerge, presumably because of persisting activation of abstract lexical or semantic representations (Neill, 1997; Tipper \& Cranston, 1985). A plausible account of the present results is, then, that the mechanisms underlying negative priming were engaged in all three present experiments, but not sufficiently so to outweigh the facilitatory effects of persisting activation in Experiments 1B and 2.

Tipper and Cranston (1985) suggested that activated distractor representations are blocked from response mechanisms during selective attention to the prime target but remain activated. If the probe target is unaccompanied by a distractor, subjects may relinquish their "selection set," revealing the facilitatory effect of persisting activation. Neill and Valdes (1992; Neill, Valdes, Terry, \& Gorfein, 1992) suggested that negative priming is caused instead by the probe target's cuing the retrieval of how a similar stimulus was recently processed. This episodic retrieval theory accounts for the reversal of negative priming to positive in two ways: (1) In the absence of a distractor, controlled algorithmic processing of the probe target may proceed too quickly to be influenced by retrieval of past processing episodes; (2) absence of a distractor may change the retrieval context sufficiently from the encoded prime context so that retrieval does not occur (Neill, 1997). ${ }^{2}$ Again, in the absence of episodic retrieval, facilitation may occur from persisting semantic activation.

As noted by Milliken et al. (1998; Milliken et al., 1994), negative priming by a single masked word requires some modification of both the inhibitory and episodic retrieval theories as initially formulated. According to the inhibitory theory as initially proposed by Neill (1977; Neill \& Westberry, 1987) and Tipper (1985; Tipper \& Cranston, 1985), distractor processing is inhibited during a prime trial in order to resolve conflict with current target processing. Because there was no primetrial target in the present procedures, negative priming clearly did not require selective attention to a prime-trial target. Houghton and Tipper (1994) presented a connectionist model of inhibitory processes that can, however, account for negative priming here. In this model, selective attention is accomplished by matching stimulus inputs to a representation of the relevant target features. The mismatch between the distractor and the target template results in inhibitory feedback to features of the distractor. Because a target template (e.g., "red word") would already be active, features of the prime word would presumably be inhibited because of the mismatch, despite the absence of a concurrent prime-trial target. A weakness of this approach, however, is that inhibition here serves to reverse the initial activation of distractor representation, so there is no convenient explanation for the reversal to positive priming if the probe target is unaccompanied by a distractor.

Neill and Valdes (1992; Neill et al., 1992) suggested that an episodic memory of the prime trial might include explicit response information ("ignore this") about the distractor stimulus. It seems somewhat unlikely that explicit response information would be incorporated into an episode in which the subject is unaware of the priming stimulus. On the other hand, Neill and Valdes also suggested that an ignored stimulus might cause negative priming because it is represented in the retrieved processing episode without any direct response information at all. A recent modification of the episodic retrieval theory, transfer-inappropriate processing, suggests that negative priming results when episodic retrieval causes a reinstatement of previous processing that is incompatible with the immediate task requirement (Neill \& Mathis, 1998). Hence, even an attended prime can cause negative priming if its processing is sufficiently different from that required by the probe target (cf. Wood \& Milliken, 1998).

Finally, it may be noted that Milliken et al. (1998) offer yet another approach to explaining negative priming. According to their temporal discrimination theory, processing difficulty encourages a "novelty bias" favoring an unrepeated stimulus. Hence, if the probe target is not 
accompanied by a distractor, processing may benefit from repetition of even an ignored prime. However, if the probe target is accompanied by a distractor, the novelty bias will tend to favor a relatively new stimulus (unrepeated condition) over the recently ignored stimulus.

As noted by Milliken et al. (1998), the temporal discrimination theory is akin to the episodic retrieval theory proposed by Neill and Valdes (1992; Neill et al., 1992), in that both theories depend more on retrospective processes, in contrast to the more directly proactive effect hypothesized of inhibition. However, the two theories also appear to make quite distinctive predictions: According to the episodic retrieval theory, retrieval of processing episodes also contributes to facilitation from repeating the same target (repetition priming). Hence, conditions that favor episodic retrieval should enhance both repetition priming and negative priming. In contrast, a novelty bias should diminish the benefits of repeating the same target, and repetition priming and negative priming should thus be inversely related. Unfortunately, the extant literature is indecisive on this question, with some experiments yielding an inverse relation (e.g., Malley \& Strayer, $1995)$ and other experiments yielding a positive relation (e.g., Neill, 1997) as a function of experimental manipulations.

\section{REFERENCES}

Besner, D., \& Swan, M. (1982). Models of lexical access in visual word recognition. Quarterly Journal of Experimental Psychology, 34A, 313-325.

Houghton, G., \& TipPER, S. P. (1994). A model of inhibitory mechanisms in selective attention. In D. Dagenbach \& T. H. Carr (Eds.), Inhibitory processes in attention, memory, and language (pp. 53-112). San Diego: Academic Press.

LowE, D. G. (1979). Strategies, context, and the mechanism of response inhibition. Memory \& Cognition, 7, 382-389.

Malley, G. B., \& Strayer, D. L. (1995). Effects of stimulus repetition on positive and negative identity priming. Perception \& Psychophysics, $57,657-667$

Milliken, B., \& Joordens, S. (1996). Negative priming without overt prime selection. Canadian Journal of Experimental Psychology, 50, 333-346.

Milliken, B., Joordens, S., Merikle, P., \& Seiffert, A. (1998). Selective attention: A re-evaluation of the implications of negative priming. Psychological Review, 105, 203-229.

Milliken, B., Joordens, S., Tipper, S. P., Merikle, P. M., \& SEIFFERT, A. (1994, November). Negative priming: Re-evaluating the role of probe display interference. Poster presented at the 35th Annual Meeting of the Psychonomic Society, St. Louis

MoORE, C. M. (1994). Negative priming depends on probe-trial conflict: Where has all the inhibition gone? Perception \& Psychophysics, 56, 133-147.

NEILL, W. T. (1977). Inhibitory and facilitatory processes in selective attention. Journal of Experimental Psychology: Human Perception \& Performance, 3, 444-450.

NEILL, W. T. (1997). Episodic retrieval in negative priming and repeti- tion priming. Journal of Experimental Psychology: Learning, Memory, \& Cognition, 23, 1291-1305.

Neill, W. T., Kahan, T. A., \& VerWys, C. A. (1996, November). Reversal of lexical priming by probe interference. Paper presented at the 37th Annual Meeting of the Psychonomic Society, Chicago.

NeILl, W. T., \& MathIS, K. M. (1998). Transfer-inappropriate processing: Negative priming and related phenomena. In D. L. Medin (Ed.), The psychology of learning and motivation: Advances in research and theory (Vol. 38, pp. 1-44). San Diego: Academic Press.

Neill, W. T., Terry, K. M., \& Valoes, L. A. (1994). Negative priming without probe selection. Psychonomic Bulletin \& Review, 1, 119-121.

NeILL, W. T., \& VALDES, L. A. (1992). The persistence of negative priming: Steady-state or decay? Journal of Experimental Psychology: Learning, Memory, \& Cognition, 18, 565-576.

NeILl, W. T., \& VAldes, L. A. (1996). Facilitatory and inhibitory aspects of attention. In A. F. Kramer, M. G. H. Coles, \& G. D. Logan (Eds.), Converging operations in the study of visual selective attention (pp. 77-106). Washington, DC: American Psychological Association.

Neill, W. T., Valdes, L. A., Terry, K. M., \& Gorfein, D. S. (1992). The persistence of negative priming: II. Evidence for episodic trace retrieval. Journal of Experimental Psychology: Learning, Memory, \& Cognition, 18, 993-1000.

NeiLL, W. T., \& Westberry, R. L. (1987). Selective attention and the suppression of cognitive noise. Journal of Experimental Psychology: Learning, Memory, \& Cognition, 13, 327-334.

NORRIS, D. (1984). The effects of frequency, repetition and stimulus quality in visual word recognition. Quarterly.Journal of Experimental Psychology, 36A, 507-518.

SCHNEIDER, W. (1988). Micro Experimental Laboratory: An integrated system for IBM PC compatibles. Behavior Research Methods, Instruments, \& Computers, 20, 206-217.

TIPPER, S. P. (1985). The negative priming effect: Inhibitory priming by ignored objects. Quarterly Journal of Experimental Psychology, 37A, 571-590.

TIPPER, S. P., \& BAYLIS, G. C. (1987). Individual differences in selective attention: The relation of priming and interference to cognitive failure. Personality \& Individual Differences, 8, 667-675.

TiPPer, S. P., \& Cranston, M. (1985). Selective attention and priming: Inhibitory and facilitatory effects of ignored primes. Quarterly Journal of Experimental Psychology, 37A, 581-611.

TIPPER, S. P., \& DrIVER, J. (1988). Negative priming between pictures and words in a selective attention task: Evidence for semantic processing of ignored stimuli. Memory \& Cognition, 16, 64-70.

Wood, T. J., \& MLLLIKEN, B. (1998). Negative priming without ignoring. Psychonomic Bulletin \& Review, 5, 470-475.

YEE, P. L. (1991). Semantic inhibition of ignored words during a figure classification task. Quarterly Journal of Experimental Psychology, 43A, 127-153.

\section{NOTES}

1. Experiment 2 was chronologically the earliest of the three experiments, and so least likely to be contaminated by subjects' experience in masked word-identification experiments.

2. Applied to the present results and those of Milliken et al. (1998; Milliken et al., 1994), contextual similarity would require the assumption that it is the number of ignored words during target processing ( 0 vs. 1) rather than total number of words ( 1 vs. 2) that determines similarity to the priming episode (one ignored word).

(Manuscript received August 21, 1997; revision accepted for publication May 6, 1998.) 